\title{
Failure of oral thiomalate to act as an alternative to intramuscular gold in rheumatoid arthritis
}

\author{
S R RUDGE, D PERRETT, AND M KELLY
}

From the Rheumatology Department, Newham General Hospital, London; The London Hospitaţ Whitechapel, London; and the Medical Unit, St Bartholomew's Hospital, London

SUMMARY Ten patients with active rheumatoid arthritis (RA) were entered into a pilot study ta evaluate the effectiveness of thiomalic acid as a disease modifying agent and to assess its toxicity Oral thiomalic acid (100 mg) was given daily for up to six months. Changes in disease activitio were recorded monthly and all side effects noted. No patient recorded any improvement if subjective well being, pain score, or duration of early morning stiffness. No significant change occurred in articular index or haemoglobin $(\mathrm{Hb})$; the erythrocyte sedimentation rate (ESR showed a tendency to increase. Only three patients completed six months' treatment; si withdrew because of toxic reactions (three with rashes and three with severe gastrointestina $\vec{P}$ upset) and one because of lack of effect. Thiomalic acid alone appears to have no significanto antirheumatic activity and is associated with an unacceptably high incidence of adverse reactions $5_{00}^{\circ}$

A number of thiol containing drugs, including D-penicillamine and disodium aurothiomalate, have been shown to be effective antirheumatic agents. ${ }^{12}$ Recent reporis suggest that at least part of their efficacy may depend upon specific actions of the sulphydryl group, in particular effects on intracellular oxidation status, ${ }^{3}$ reduced glutathione levels, ${ }^{4}$ and oxygen derived free radicals. ${ }^{5}$ We have previously shown that immediately after intramuscular injection disodium aurothiomalate dissociates to form free thiomalate and protein bound gold. Preliminary data on a small number of patients published by Munthe and Jellum in 1980 suggested that sodium thiomalate, given orally, might be as effective and less toxic than disodium aurothiomalate. ${ }^{6}$ We have, therefore, undertaken a pilot study to evaluate the clinical and laboratory changes that occur when patients with RA are treated with oral thiomalic acid.

\section{Patients and methods}

Ten patients were entered into the study. All had classical or definite RA according to the criteria of the American Rheumatism Association and had failed to respond to simple analgesics or non-

Äccepted for publication 14 September 1987.

Correspondence to Dr S R Rudge, Rheumatology Department, Newham General Hospital, Glen Road, Plaistow, London E13 8SL. steroidal anti-inflammatory drugs. None had reอ̄ ceived gold or penicillamine in the preceding sip months and none was currently receiving steroids The group consisted of six women and four men $\vec{\odot}$ mean age 56.3 years (range 36-64), and meaw disease duration six years (range six months to 12 years). All patients were RA latex positive before. the start of thiomalic acid therapy.

\section{A S S ESSM EN TS}

Clinical and laboratory assessments were carried out monthly for a period of six months. Clinica measurements included the Ritchie articular index duration of early morning stiffness in minutes, paio score recorded on a horizontal visual analogue scales and hand grip strength in $\mathrm{mmHg}$. Laboratory measurements included haemoglobin $(\mathrm{Hb})$, ESRN platelet count, and rheumatoid factor titre. Urea and electrolyte concentrations, liver function testsc and urine analysis were performed at each visit. A monthly index of disease activity was calculate $\bar{q}$ using the technique of multivariate analysis dee scribed by Mallya and Mace. ${ }^{7}$ Treatment wa市 stopped if a potentially serious adverse effect became apparent or if a patient felt unable to continue because of side effects.

\section{R U G REG I M E N}

Thiomalic acid (mercaptosuccinic acid, Cat. NQ M-3754, grade 1) was obtained from Sigma Chemi 
cal Company (Dorset, UK) and packed into gelatin capsules by the hospital pharmacy. Each patient was given $100 \mathrm{mg}$ thiomalic acid daily and instructed to take the capsules on an empty stomach. All patients were allowed a single supplementary non-steroidal anti-inflammatory drug, which was continued unaltered throughout the study.

\section{ABSORPTION OF THIOMALIC ACID}

Plasma and urine profiles of free thiomalate were measured after a single oral dose of $100 \mathrm{mg}$ thiomalic acid in six normal subjects and in two patients one month after starting treatment. All subjects were fasting. Samples were collected and assayed by high performance liquid chromatography and electrochemical detection as described previously. ${ }^{8}$

All participants gave informed consent to the study, which was approved by the hospital ethical committee. Comparison of clinical and biochemical assessments before and after treatment was made by Student's $t$ test for paired samples.

\section{Results}

CLIN I CAL STUDIES

Only three patients completed six months' treatment with oral thiomalic acid. Six patients withdrew because of toxic reactions, three with rashes and three with severe gastrointestinal upset. Fig. 1 shows the timing of the development of side effects in relation to the duration of treatment. Patients 3 and 5 developed a scaly, erythematous, pruritic rash on the face, scalp, and trunk three months after starting treatment. In both cases the rash subsided within two weeks of discontinuing treatment. After five months' treatment patient 7 developed painful superficial blisters over the upper trunk, which were

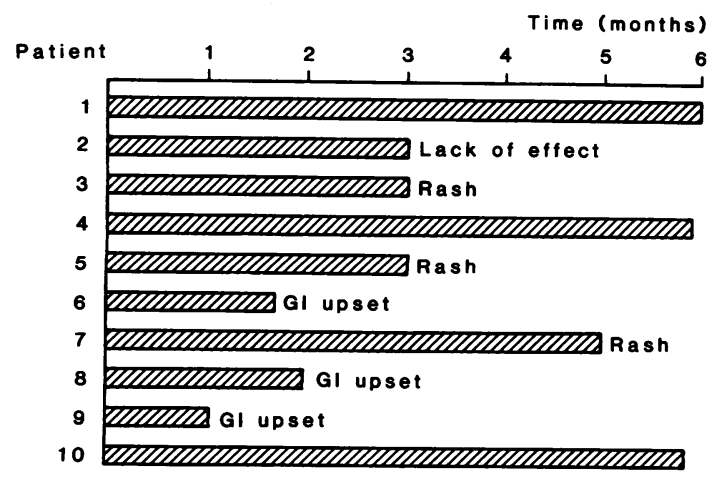

Fig. 1 Time of onset of side effects in patients receiving oral thiomalic acid $100 \mathrm{mg}$ daily. GI=gastrointestinal. diagnosed as pemphigus. She required treatment with high dose steroids ( $60 \mathrm{mg}$ daily) and azathioprine (150 mg daily) to control the eruption. Epigastric pain, which promptly subsided after discontinuation of treatment, occurred in three patients. The epigastric discomfort returned on rechallenge in one patient. None had a previous history of peptic ulceration. One further patient withdrew because of the lack of effect. No renal, haematological, or hepatic toxicity was recorded.

Table 1 shows the mean values of the clinical and biochemical parameters measured before and after treatment in all 10 patients. There was no significant improvement in any of the parameters measured. Mean ESR showed a tendency to increase, though this was not significant $(p<0.06)$. There was no significant change in rheumatoid factor titre during the course of the study.

Fig. 2 shows the changes in ESR, articular index, and index of disease activity, recorded in the three patients who completed 24 weeks' therapy. No significant improvement occurred in any of these parameters.

\section{A BSORPTION STUDIES}

Free thiomalate was detected in the plasma and urine of all normal controls and both patients with rheumatoid arthritis. Fig. 3 shows the plasma profiles of free thiomalate in the two patients compared with the range in normal subjects. The mean (SD) percentage recovery of free thiomalate from the urine in eight hours was $14.5(4.5) \%$ in normals compared with $5.2 \%$ and $4.6 \%$ respectively in the two patients with rheumatoid arthritis. When, in a separate experiment, thiomalic acid was taken with food by three normal subjects, both plasma and urinary levels of free thiomalate were undetectable.

Table 1 Clinical and biochemical assessment before and after treatment in 10 patients

\begin{tabular}{llll}
\hline Measurement & $\begin{array}{l}\text { Before } \\
\text { treatment }\end{array}$ & $\begin{array}{l}\text { After } \\
\text { treatment }\end{array}$ & $\begin{array}{l}\text { Significance } \\
\text { of difference } \\
(p<)\end{array}$ \\
\hline $\begin{array}{l}\text { Early morning } \\
\quad \text { stiffness }\end{array}$ & $59.5(56.6)^{*}$ & $70.0(72 \cdot 2)$ & 0.72 \\
$\begin{array}{l}\text { Pain score } \\
\text { Grip strength }\end{array}$ & $5.2(1.8)$ & $5.8(2.6)$ & 0.56 \\
$\quad 126(61)$ & $117(52)$ & 0.73 \\
Articular index & $10.4(3.1)$ & $10.0(4 \cdot 1)$ & 0.71 \\
Hb (g/1) & $118(18)$ & $11.3(1.5)$ & 0.30 \\
ESR (mm/h) & $46(17)$ & $56(20)$ & 0.06 \\
Index of & $2.6(0.4)$ & $2.6(0.4)$ & 0.62 \\
$\quad$ disease activity & & & \\
\hline
\end{tabular}

${ }^{*}$ Results are presented as mean (SD). 
A

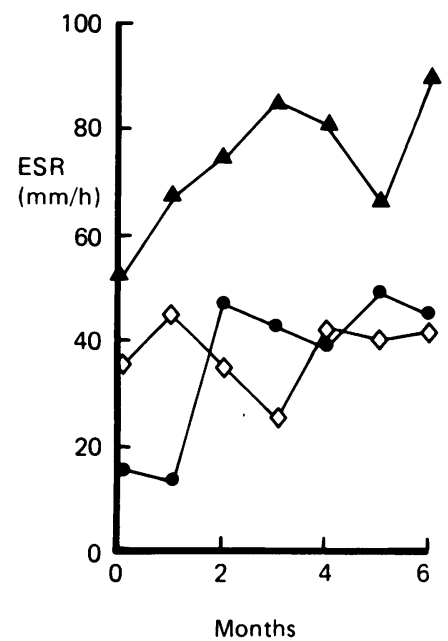

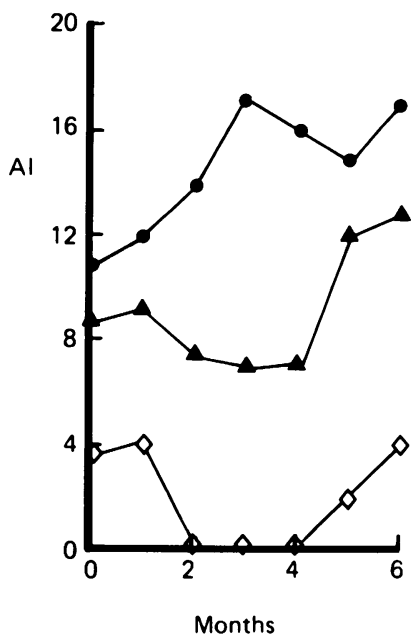

C

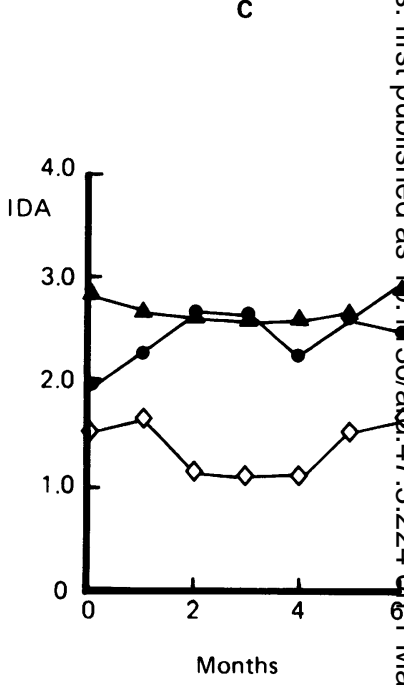

Fig. 2 Changes in $(A) E S R,(B)$ articular index $(A I)$, and $(C)$ index of disease activity $(I D A)$ in three patients who completed six months' treatment with oral thiomalic acid.

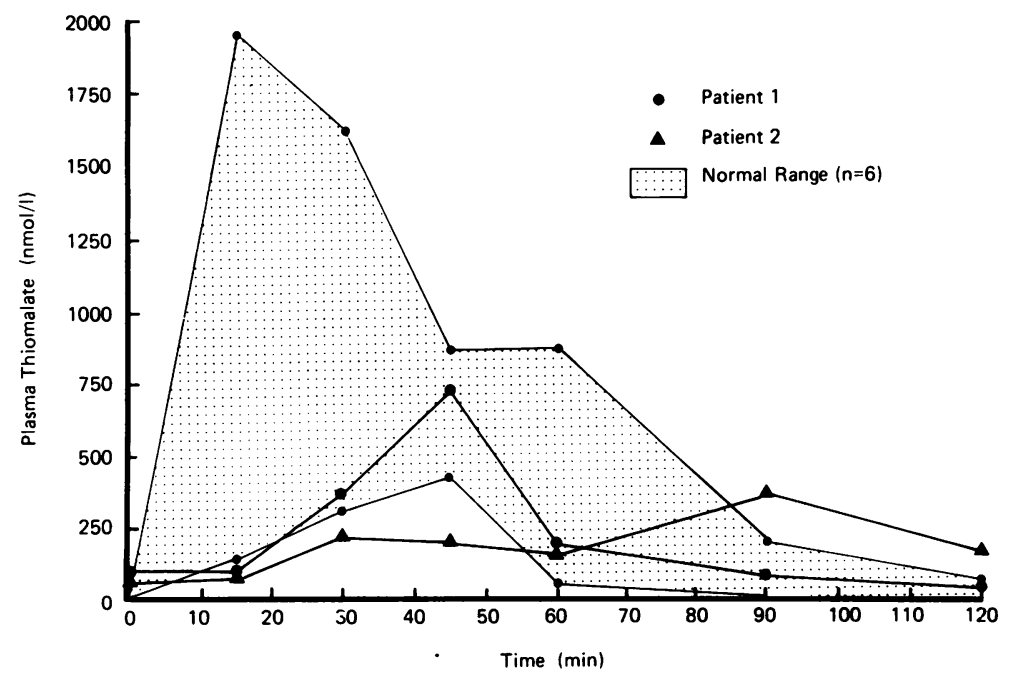

Fig. 3 Plasma profiles of free thiomalate after a single oral dose of $100 \mathrm{mg}$ thiomalic acid in two patients with RA. Hatched area showed the range in six normal subjects.

\section{Discussion}

The results of this pilot study fail to show any significant effect of thiomalic acid alone on disease activity in patients with RA. The unacceptable level of side effects made it unethical to continue or increase the numbers further. This is in contrast with the five patients described by Munthe and Jellum, ${ }^{6}$ who experienced no adverse reactions when given
$200 \mathrm{mg}$ sodium thiomalate daily for between 19 weeks and five months. Disease activity was said to have progressed in only one patient. Unfortunately, no further details of this study have been published As sodium thiomalate will rapidly dissociate in bodo fluids to thiomalate ion, as will thiomalic acid, it unlikely that the different chemical form of thiom $\mathbb{Q}$ late employed would account for these clinicat differences. 
The apparent lack of effect of thiomalate could be explained by poor absorption of the capsules or by the dose being too small. Absorption studies confirm that thiomalate was rapidly absorbed, reaching plasma levels comparable with those achieved after a single intramuscular dose of sodium aurothiomalate, provided that the capsule was taken on an empty stomach. ${ }^{9}$ The dose given amounted to 700 $\mathrm{mg}$ thiomalic acid weekly, 36 times that normally given by intramuscular injection in the form of disodium aurothiomalate. It is unlikely, therefore, that the dose was too small, and the development of side effects in six patients precluded any increase.

We and others have suggested that at least part of the activity of disodium aurothiomalate resides in the thiol moiety. ${ }^{10}{ }^{11}$ It is known that disodium aurothiomalate dissociates immediately after injection to form free thiomalate and protein bound gold and that this dissociation is almost complete. ${ }^{12}$ Studies in the 1940s showed that simple gold salts, such as gold chloride, were ineffective in RA. ${ }^{13}$ Our own results suggest that thiomalic acid alone is also ineffective. It thus appears that both the gold and the thiol moieties need to be present for the drug to exert an antirheumatic effect. Whether they or their metabolites achieve this effect independently or combine to form an, as yet, unidentified polymer remains uncertain. It is clear, however, from the work of Grootveld and Sadler, that disodium aurothiomalate can exist in more than one polymeric form. ${ }^{14}$

What our study does highlight, however, is the probable role of the thiol moiety in the development of adverse reactions. Both the time of onset and the nature of the rashes were similar to those reported with other thiol compounds, and patient 3 developed an almost identical scaly pruritic rash over the face and forearms when treatment was subsequently started with D-penicillamine. Pemphigus has been reported in up to $9 \%$ of patients with RA treated with D-penicillamine ${ }^{15}$ and is also recognised as a complication of captopril therapy. ${ }^{16}$ The gastrointestinal complications appear to be a direct local effect of thiols on the gut mucosa. An earlier report describes the formation of disulphide bonds between D-penicillamine and gut wall proteins, leading to severe gastrointestinal upset. ${ }^{17}$

Our small pilot study, therefore, suggests that the thiol moiety of disodium aurothiomalate in itself has no direct antirheumatic activity but may well be responsible for much of the toxicity of chrysotherapy. The known contamination of ampoules of disodium aurothiomalate by variable amounts of free thiomalate ${ }^{18}$ may contribute to this toxicity.

\section{References}

1 Empire Rheumatism Council. Gold therapy in rheumatoid arthritis; final report of a multi-centre controlled trial. Ann Rheum Dis 1961; 20: 315-33.

2 Andrews F M, Camp A V, Dat A T, et al. Controlled trial of Dpenicillamine in severe rheumatoid arthritis. Lancet 1973; i: 275-80.

3 Jaffe I A. Thiol compounds with penicillamine-like activity and possible mode of action in rheumatoid arthritis. Clin Rheum Dis 1980; 6: 633-45.

4 Munthe E, Kåss E, Jellum E. D-penicillamine-induced increase in intra-cellular glutathione correlating to clinical response in rheumatoid arthritis. The Journal of Rheumatology Supplement 1981; 7: 14-19.

5 Cuperus R A, Muijsers A O, Wever R. Antiarthritic drugs containing thiol groups scavenge hypochlorite and inhibit its formation by myeloperoxidase from human leucocytes. Arthritis Rheum 1985; 28: 1228-33.

6 Munthe E, Jellum E. Tolerance and effectiveness of sodium thiomalate without gold in rheumatoid arthritis. Scand $J$ Rheumatol [Suppl] 1980; 33: 42.

7 Mallya R K, Mace B E. The assessment of disease activity in rheumatoid arthritis using a multivariate analysis. Rheumatol Rehabil 1981; 20: 14-17.

8 Rudge S R, Perrett D, Drury P L, et al. The determination of thiomalate in physiological fluids by high-performance liquid chromatography and electrochemical detection. Journal of Pharmaceutical and Biomedical Analysis 1983; 1: 205-10.

9 Rudge S R. Perrett D, Swannell A J. Free thiomalate in plasma and urine of patients receiving sodium thiomalate. Ann Rheum Dis 1984; 43: 66-9.

10 Drury P L, Rudge S R, Perrett D. Structural requirements for activity of certain specific antirheumatic drugs: More than a simple thiol group? Br J Rheumatol 1984; 23: 100-6.

11 Forestier J. Rheumatoid arthritis and its treatment by gold salts. J Lab Clin Med 1935; 20: 827-40.

12 Rudge S R. Studies on the thiol moiety of disodium aurothiomalate in patients with rheumatoid arthritis. Nottingham, 1984. (D M thesis).

13 Freyberg $\mathrm{R} \mathrm{H}$. The place of gold compounds in the treatment of rheumatoid arthritis. J Chronic Dis 1957; 5: 723-32.

14 Grootveld M C, Sadler P J. Differences between the structure of the anti-arthritic gold drug 'Myocrisin' in the solid state and in solution: a kinetic study of dissolution. J Inorg Biochem 1983; 19: $51-4$.

15 Marsden R A, Hill H, Mowat A G et al. Penicillamine induced pemphigus. Proc R Soc Med 1977; 70 (suppl 3): 103-6.

16 Ryan T J. Diseases of the skin. In: Weatherall D J, Ledingham J G G, Warrell D A, eds. Oxford textbook of medicine. Oxford: Oxford University Press, 1983: 20-69.

17 Perrett D. An outline of D-penicillamine metabolism. Proc $R$ Soc Med 1977; 70 (suppl 3): 61-4.

18 Rudge S R, Perrett D, Swannell A J, Drury P L. Circulating thiomalate after administration of disodium aurothiomalate: Impurity or active metabolite? J Rheumatol 1984; 11: 150-2. 